\title{
Mechanical and Metallurgical Characterization of Al/Ceramic MMC
}

\author{
G. Srinivas Kumar, Y. Venkata Mohana Reddy, B. Chandra Mohan Reddy
}

\begin{abstract}
Aluminum amalgam MMCs are ahead of time abundant acknowledgment for vehicle, modern, and aviation application due to their low thickness, high and great basic quality inflexibility. In the present work, an exertion is made to plan and assess the mechanical properties of Al6061-SiC/Graphite half breed composites. The composites were primed by means of stir casting process in which amount of fortification is varied from $2-10 \%$ in steps of 3, 5, $7 \mathrm{wt} \%$. The primed composites are characterized as per standards. The scattered Graphite and SiC in Al6061 combination contributed in improving the rigidity of the composites. The SEMs of the examples showed uniform conveyance of the fortification particles in the lattice with no voids.
\end{abstract}

Keywords: MMC, Al6061, SiC/Graphite, fortification

\section{INTRODUCTION}

Aluminum amalgams are generally utilized for aviation and car segments because of their high solidarity to-weight proportion. The qualities of aluminum compounds can be upgraded by including fitting extents of metal and/or non-metal fortifications and creating them as metal matrix composites (MMC). Scholars have investigated aluminum alloy-based MMCs to meet recent demands for advanced engineering applications. Mariappan et al (2015) revealed that as the stiffness of the composites increased, tensile strength also increased and the amount of reinforcement decreased. The stirred-cast MMC had a high hardness and compressive strength due to low hardness, low crack formation. As. Hamdi et al (2002), direct treatment in cerium solutions doesn't give great erosion security to aluminum composites. Besides, pickles increment the capacity of cerium to disperse equitably over the outside of the material. s. Kannan et al. (2006) found that the matrix material affects the depth of the plasticically deformed area below the machined surface. Geometrical defects such as microcracks, widows, pits, and craters were mainly caused by particulate fractures and / or pull-outs and interfacial deballing.

S. Tzmatzis et al (2008), stated that the distribution of SiC particle in the metal matrix was enhanced symbolically when composites were formed via the roto-process and suggested that the reinforcement distribution was improved by higher hairs. The cutting effect is the result of a specially designed

Revised Manuscript Received on February 05, 2020.

* Correspondence Author

G. Srinivas Kumar, Research Scholar, JNTUCEA, Anantapuramu, India Email: srin.8045@gmail.com

Dr. Y. Venkata Mohana Reddy, Professor, G. Pulla Reddy Engineering College, Kurnool, India.. Email: yvmr06@gmail.com

Dr. B. Chandra Mohan Reddy, Associate Professor, Jawaharlal Nehru Technological University, Anantapuramu, India. Email: cmr_b@yahoo.com

(c) The Authors. Published by Blue Eyes Intelligence Engineering and Sciences Publication (BEIESP). This is an open access article under the CC BY-NC-ND license (http://creativecommons.org/licenses/by-nc-nd/4.0/) twin-screw machine at BCAST. A. C. Reddy et al (2010), expressed that alloying components, for example, $\mathrm{Si}, \mathrm{Fe}, \mathrm{Mg}$, and Qi assumed a critical job on the mechanical properties of $\mathrm{Al} / \mathrm{SiC}$ composites. Mg has improved the practicality among $\mathrm{Al}$ and $\mathrm{SiC}$ particles by lessening the $\mathrm{SiO}$ layer on the $\mathrm{SiC}$ surface. M. V. Krishna et al (2014), seen that the mechanical properties of rigidity, for example, composites of composites are additionally enormously affected by weight contrasts. DM Patolia et al (2015), effectively created MMC utilizing the mix throwing method with uniform conveyance of zirconium dioxide particles. The rate lengthening of MMC diminished with an expansion in $\mathrm{ZrO} 2$ content, which affirmed that $\mathrm{ZrO} 2$ expanded weakness. M. Sambhathakumar et al. (2016), presumed that the smaller scale hardness of the composite material was expanded with an expansion in support from 0 to $15 \%$ of the volume. In pliable tests, the composite with $10 \%$ volume $\mathrm{SiC}$ and $\mathrm{TiC}$ demonstrated a greatest quality of $240 \mathrm{MPa}$, an expansion of $240 \mathrm{MPa}$ (33\%) contrasted with the base combination. S. Dhalipen et al, (2018) found good intercepial bonding between particles and matrix. In addition to zircon sand ( $\mathrm{ZrSiO} 4)$ and rice husk ash (RHA) particles, the hardness of the aggregate increases gradually as well as the wear resistance. S.K.Nayak et al, (2018) seen that united with 2.75 vol. \% Of zirconia shows the most noteworthy elasticity $(132.008 \mathrm{MPa})$ while composite with $4.5 \mathrm{vol}$. \% Of zirconia shows the most reduced elasticity (91.263MPa)

\section{EXPERIMENTAL DETAILS}

\section{A. Materials}

The matrix material is Al6061 and the fortification material selected were $\mathrm{SiC}$, constituent part of $10 \mu \mathrm{m} \&$ Graphite of particle size $16 \mu \mathrm{m}$.

\section{B. Procedure for Material Preparation}

Al-6061 have taken in a chemical composition shown in Table 1.

Table 1: Chemical Composition Al6061

\begin{tabular}{|c|c|}
\hline Element & Amount (wt \%) \\
\hline Aluminium & 96.85 \\
\hline Magnesium & 0.9 \\
\hline Silicon & 0.7 \\
\hline Iron & 0.6 \\
\hline Copper & 0.30 \\
\hline Chromium & 0.25 \\
\hline Zinc & 0.20 \\
\hline Titanium & 0.10 \\
\hline Manganese & 0.05 \\
\hline Others & 0.05 \\
\hline
\end{tabular}


It will be melted in the resistance furnace. The crucible is made of graphite. Already manufacture of composite, softening misfortunes of a combination constituent are taken into a thought. The composite will fluxed with coverall the forestall dressing. The molten fluid composite was degasified utilizing tetrachlorethane. The crucible is changed with the sodium is removed from the heater. The liquid fluid of matix is as semi strong state, by chilling off to, underneath the liquidous temperature. During this procedure, the liquid fluid is included by the pre-warmed fortifications (which is $470^{\circ} \mathrm{C}$ for $1 / 2$ hour) $\mathrm{SiC}$ and Graphite particulates. The volume grinding are $\mathrm{SiC}$ and Graphite(3\%, 5\%, 7\%). The normal size $\mathrm{SiC}$ and Graphite is $10 \mu \mathrm{m}$ and $16 \mu \mathrm{m}$. Liquid $\mathrm{SiC}$ and Al6061 particles are blended physically at normal interims. After an adequate mixing physically on a timeframe, semi-strong condition of fluid will be warmed to an absolutely fluid state in obstruction heater, likewise a programmed mechanical blending is additionally completed for around 15 minutes at $600 \mathrm{rpm}$ to transform the fluid into standardized blend. Utilizing a transducer which is of plunging type, temperature is estimated. At long last, in the wake of achieving a legitimate blending of matix and support, it is filled the preheated cast iron shape in nearness of gravity.

\section{Characterization}

\section{Tensile Testing}

Tractable test tests have been set up by machining the cast tests to the ideal sizes according to ASTM standard. The rigidity of the examples was assessed in the Universal Testing Machine.

\section{Wear Testing}

Table 2: UTM Results for specimens of 3\%, $5 \%$ \& $7 \%$

\begin{tabular}{|c|c|c|c|c|c|c|c|c|c|c|c|c|}
\hline & $\mathbf{m}_{\mathrm{E}}$ & $\mathbf{R}_{\mathbf{p} 0.2}$ & $\mathbf{R}_{\mathbf{e H}}$ & $\mathbf{R}_{\mathbf{m}}$ & $\mathbf{A}_{\mathrm{g}}$ & $\mathbf{A}_{\mathrm{gt}}$ & $\mathbf{R}_{\mathbf{B}}$ & $\mathbf{A}_{30 \mathrm{~mm}}$ & $\mathbf{A}_{t}$ & $\mathbf{a}_{0}$ & $\mathbf{b}_{0}$ & $\mathrm{~S}_{0}$ \\
\hline & GPa & MPa & MPa & MPa & $\%$ & $\%$ & MPa & $\%$ & $\%$ & $\mathbf{m m}$ & $\mathbf{m m}$ & $\mathbf{m m}^{2}$ \\
\hline 3 & 17.82608 & 88.81032 & & 102.8026 & 0.723652 & 1.086587 & 97.55624 & 0.821875 & 1.155379 & 4.11 & 6.41 & 26.3451 \\
\hline 5 & 5.800845 & 83.0784 & 83.3004 & 83.3004 & 0.222627 & 0.947822 & 16.54582 & 2.008178 & 1.582599 & 3.99 & 6.43 & 25.6557 \\
\hline 7 & 9.96824 & 84.77356 & & 99.86667 & 0.969328 & 1.589721 & 27.94198 & 2.136246 & 2.0351 & 4 & 6.46 & 25.84 \\
\hline
\end{tabular}

\section{B. Analysis of wear Test}

The graphical portrayal of the above information is appeared in Fig1,2 \&3.

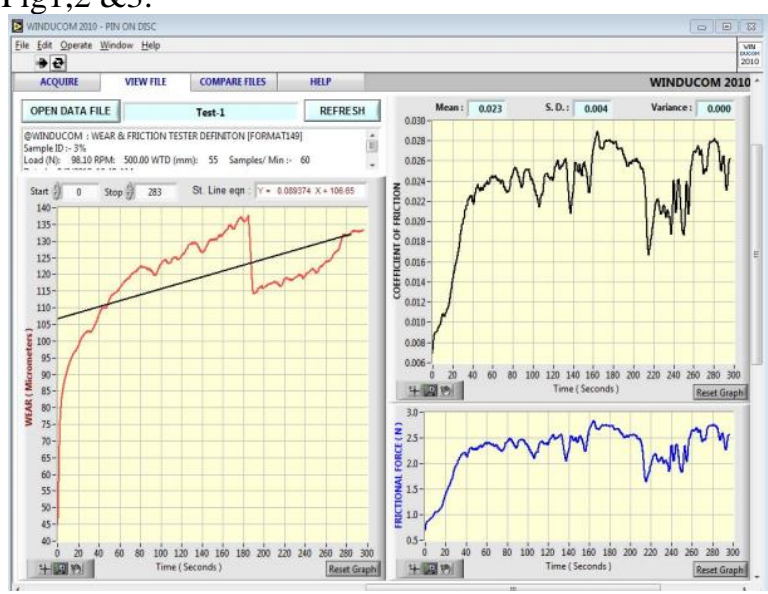

Fig1: Wear Test for $3 \mathrm{Vol} \%$ specimen

From the got information it is seen that the C.O.F of Sample 2 and 3 abatements with the expansion in load.
From the literature, it is seen that the wear and rubbing conduct of MMC's having Aluminum as lattice firmly relies upon the particles utilized for fortification. its size and volume portion of particles. The coefficient of erosion from the metal framework composites are high if pace of fortification molecule is low furthermore this, the wear opposition increments with expanding volume portion of fortifying particulates. In the event that the particulates utilized for fortification limited well to the matrix,the wear opposition of the composite builds consistently with increment in the volume portion of artistic particles and the basic volume division for the most part relies upon the heap applied during the wear test.

For the examination of the wear test the samples of Al6061+SiC+Graphite MMC with 30mm length and 8mm dia are made. The samples are cleaned with the $4 \mathrm{k}$ emery paper before going to test using the pin on circle process. Wear rate, frictional power and Co-proficient of grinding versus sliding separation examination is continued every sample.

\section{RESULTS AND DISCUSSION}

\section{A. Tensile Test}

The outcomes got from the elastic test were spoken to in the graphical structure underneath. From the outcome obviously the composite comprising of 3 vol.\% of $\mathrm{SiC}$ and Graphite shows most noteworthy rigidity where as the composite with 5 vol.\% of shows lower elasticity which are appeared in Table 2 .

While the C.O.F of sample 1 first increments and afterward diminishes with the expansion in load.

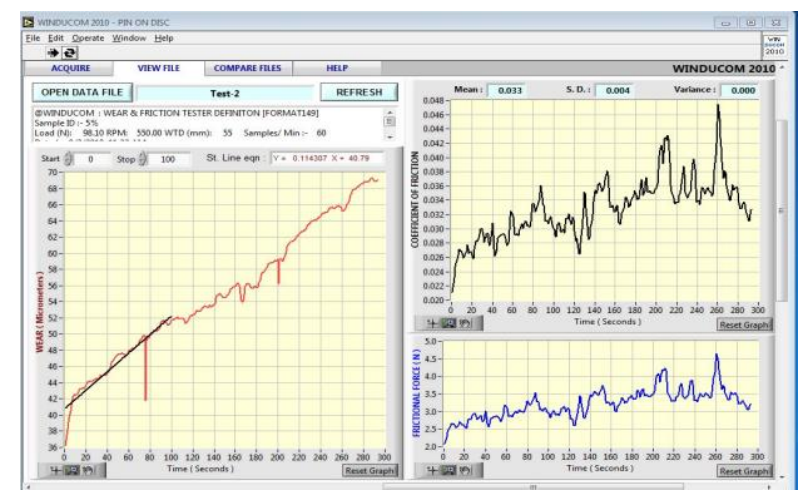

Fig2: Wear Test for 5 Vol\% specimen 


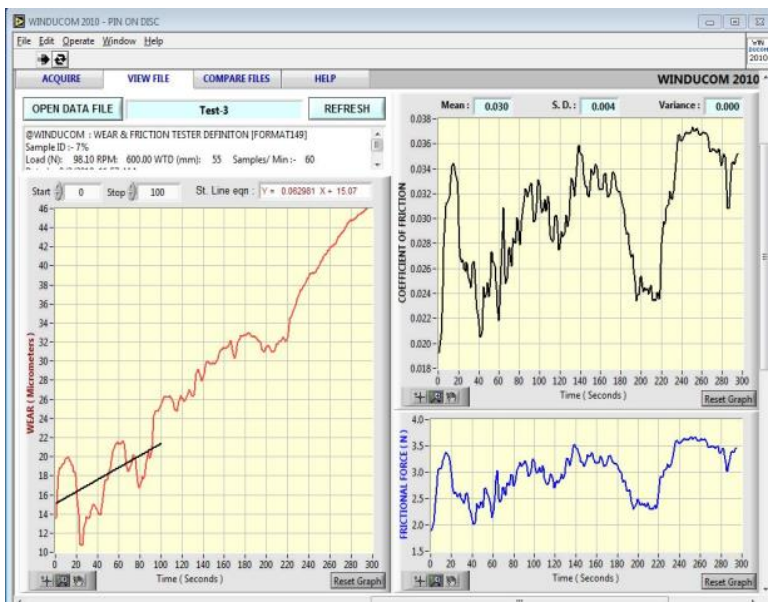

Fig3: Wear Test for 7 Vol\% specimen

\section{Microscopic Examination}

Microstructure is characterized as the structure of a readied surface or thin foil of material as uncovered by a magnifying instrument above $10 \mathrm{KX}$ amplification appeared in Fig 4(a,b,c) and 5 (d,e,f). The microstructure of a material (which can be extensively characterized into metallic, polymeric, clay and composite) can emphatically impact physical properties, for example, quality, strength, pliability, hardness, consumption opposition, high/low temperature conduct, wear obstruction, etc, which thus oversee the utilization of these materials in mechanical practice.

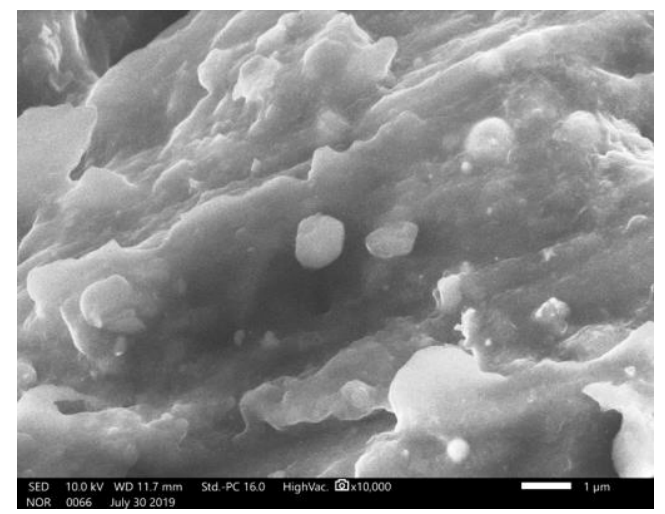

(a)

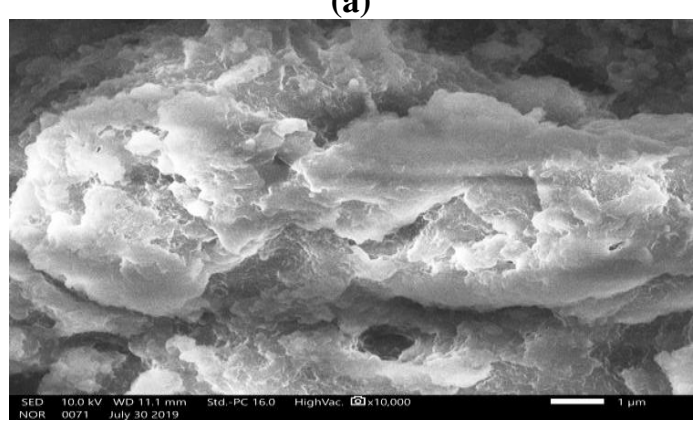

(b)

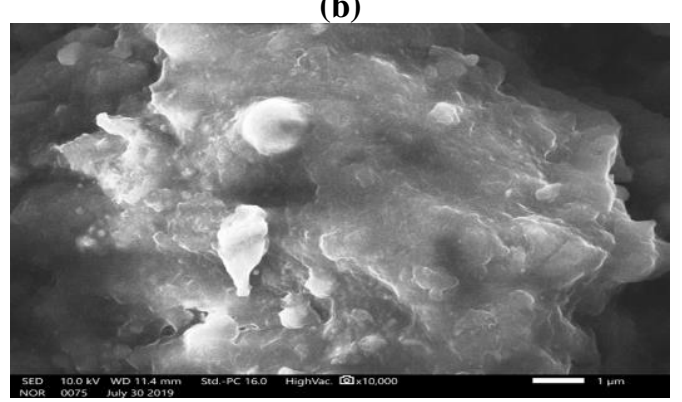

Retrieval Number: B4656129219/2020@BEIESP DOI: 10.35940/ijeat.B4656.029320 Journal Website: www.ijeat.org (c)

Fig 4 (a, b \& c): SEM Images before the wear Test for the specimens of $3 \%, 5 \% \& 7 \%$

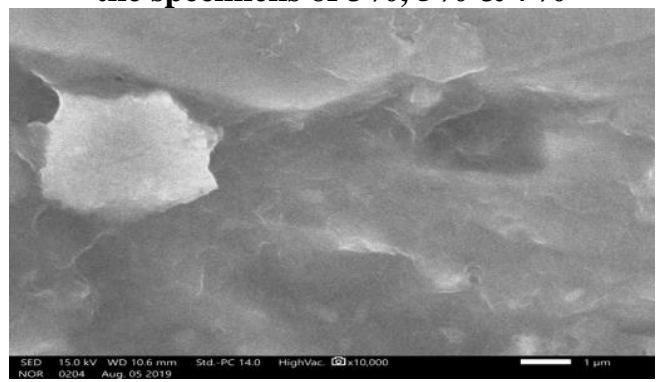

(d)

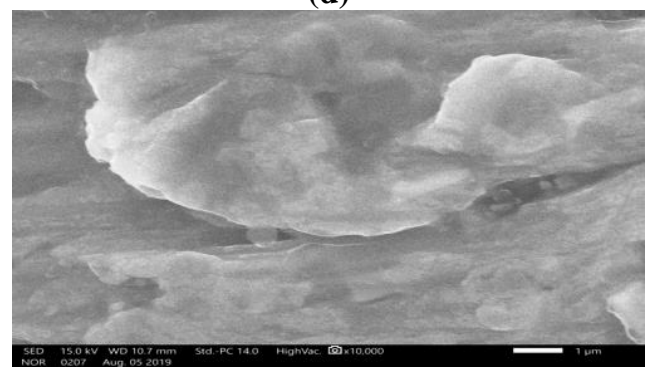

(e)

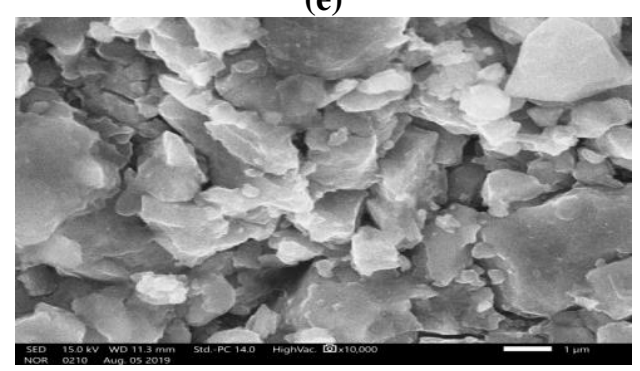

(f)

Fig 5(d, e \& f): SEM Images after the wear test for the specimens of $3 \%, 5 \% \& 7 \%$

\section{CONCLUSION}

Al6061/SiC//Graphite composite successfully fabricated The results obtained are being a soft and ductile metal shows poor wear resistance which dampens the use of aluminium in highly demanding environments. On the other hand alumina (Al2O3) is a highly refractive material shows superior wear resistance.

- The graphs obtained shows impact of measure of support on the wear rate. From the outcome unmistakably the composite comprising of 3 vol.\% of $\mathrm{SiC}$ and Graphite shows most elevated rigidity where as the composite with $5 \mathrm{vol} . \%$

- The SEM images showed the structure of alignment of the reinforcement materials before \& after the wear test.

\section{REFERENCES}

1. A.S.Hamdy, A.M Beccaria, and P. Traverso, "Corrosion protection of aluminium metal-matrix composites by cerium conversion coatings", Surf. Interface Anal. 2002; 34: 171-175. DOI: 10.1002/sia.1276

2. S. Kannan, H.A. Kishawy, " Surface characteristics of machined aluminium metal matrix composites", International Journal of Machine Tools \& Manufacture 46 (2006) 2017-2025.

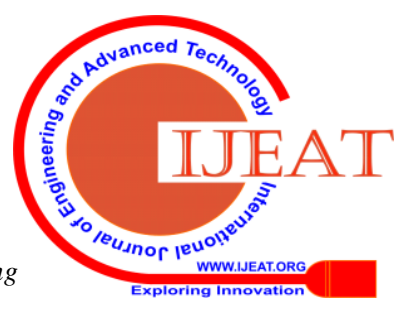


3. S. Tzamtzis, N.S. Barekar, N. Hari Babu, J. Patel, B.K. Dhindaw, Z. Fan, "Processing of advanced $\mathrm{Al} / \mathrm{SiC}$ particulate metal matrix composites under intensive shearing - A novel Rheo-process", Composites: Part A 40 (2009) 144-151, doi:10.1016/j.compositesa.2008.10.017

4. A. Chennakesava Reddy and Essa Zitoun, "Matrix Al-alloys for silicon carbide particle reinforced metal matrix composites", Indian Journal of Science and Technology, Vol. 3 No. 12 (Dec 2010, ISSN: 0974- 6846 PP- 1184 - 1187

5. M.Mariyappan, P.Sarangapani, G. Perumal and A.Sathiyamoorthi, "Improvement In Tribological Behavior Of Aluminum 356 Hybrid Metal Matrix Composites" JCHPS,ISSN: 0974-2115, Special Issue 9: April 2015, pp:98-102

6. Dharmesh M. Patoliya, Sunil Sharma, "Preparation and Characterization of Zirconium Dioxide Reinforced Aluminium Metal Matrix Composites" IJIRSET, ISSN (Print): 2347 - 6710 Vol. 4, Issue 5, May 2015,pp:3315-3321

7. Sambathkumar, M., Navaneethakrishnan, P., Ponappa, K., \& Sasikumar, K.S.K.. (2017). Mechanical and Corrosion Behavior of Al7075 (Hybrid) Metal Matrix Composites by Two Step Stir Casting Process. Latin American Journal of Solids and Structures, 14(2), 243-255.

8. S. Dhileepan, Dr.D.lenin singara velu,I.Justin antony raj, J.Sebastin joyal, "Al5083 matrix hybrid composites reinforced with zircon sand (Zrsio4)particles and rice husk (RHA) particles are synthesized by the stir 2casting method", International Research Journal of Engineering and Technology (IRJET), e-ISSN: 2395-0056, Volume: 05 Issue: 02, Feb-2018 pp:1047-1051

9. S.K.Nayak, T.Mahanta, J.K.Sahoo, and A.Mishra (2018), "Mechanical Properties and Wear Characteristics Al-ZrO2SiCp and Graphite Hybrid Metal Matrix Composites" Materials Science and Engineering.

10. M.Vamsi Krishna, Anthony.M.Xavior, "An Investigation on the Mechanical Properties of Hybrid Metal Matrix Composites", Procedia Engineering 97 ( 2014 ) 918 - 924.

\section{AUTHORS PROFILE}

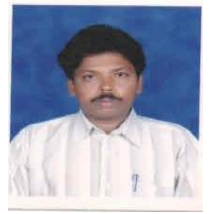

G. Srinivas Kumar is presently Pursuing Ph.D (Research Scholar) from Jawaharlal Nehru Technological University, Anantapuramu. He was born in Kurnool in Andhrapradesh, India. He graduated in B.Tech: G. Pulla Reddy Engineering college-2007, M.Tech: JNTUA, Anantapuramu -2012. His interest in Composites, Nano materials, Tribology, His research group comprises of Eight UG Students and two M.Tech students. He had published a book chapter in Springer and working on MMC and published 05 journals in international journals and 03 international conferences.

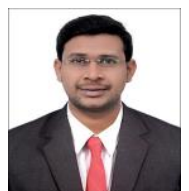

Dr Y. Venkata Mohan Reddy, is working as Professor and HOD in the Department of Mechanical Engineering, GPREC, Kurnool. His interest in Vibration and finite Element Method. His research group comprises of $2 \mathrm{PhD}$ scholars awarded and 07 Ph.D Scholars guiding and 09 M.Tech students. He had published a book chapter in Springer \& published 33 journals in international journals, 09 journals in National, and 09 international conferences and 04 national conferences.

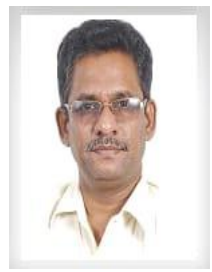

Dr.B.Chandra Mohana Reddy is presently working as Head of the department in Mech Engineering, Anantapur from 2017 to till date. His interest in Composites, Production, Tribology, Industrial Engineering and Design. His research group comprises of $8 \mathrm{PhD}$ scholars and $14 \mathrm{M}$.Tech students. He had published a book chapter in Springer \& published 25 journals in international journals and 15 international conferences. 